\title{
Visual Education of Music Course for College Students Based on Human-Computer Interaction
}

\author{
https://doi.org/10.3991/ijet.v15i02.12535 \\ Yifeng Li \\ Northeast Agricultural University, Harbin, China \\ Liyifeng1929@126.com
}

\begin{abstract}
Visual education is an emerging education method in many Chinese colleges. However, the visual education in Chinese colleges has not attached enough importance to the hands-on ability and comprehension ability of college students. To solve the problems, this paper designs and applies a visual education method for music courses in colleges based on the humancomputer interaction system. Special attention was paid to the formulation of the human-computer interaction system, which is essential for visualization of music information. Based on the master-slave mode, the human-computer interaction system introduces the cloud control into the visual education of music. The proposed method was verified through the application in a university of Nanjing, China. The results show that our method greatly boosts the acquisition of music information by college students and effectively arouses their interests in music. The research results lay the basis for wider application of visual technology in education.
\end{abstract}

Keywords-Human-computer interaction system, visual education, music education, cloud control, college students

\section{Introduction}

Visualization refers to the visual representation of an object, situation, or set of information. The visualization technology has been increasingly integrated to college education, which speeds up the information transmission, processing and perception in the eye-brain system of each student [1]. This education method, known as visual education, can effectively visualize various types of information, ranging from scientific formulas to abstract data [2]. Many colleges in China have adopted this education method. According to some college teachers, visual education makes the teaching process more clear, vivid and efficient [3].

Visual education relies on human-computer interaction to visualize a variety of teaching contents [4]. The human-computer interaction is the only interface between human and machine. A suitable human-computer interaction system for visual education must be simple to use, and multifunctional through a user-friendly interface [5]. Such a system offers the visual education the necessary interactivity and operability. 
Currently, the visual education in Chinese colleges has not attached enough importance to the hands-on ability and comprehension ability of college students. These abilities should be considered in future visual education systems $[6,7]$.

To solve the problem, this paper designs and applies a visual education method for music courses in colleges based on the human-computer interaction system. The music education was selected as the research object, because of its significant influence on the artistic taste of college students. The proposed method can arouse the interests of college students in music [8], laying the basis for wider application of visual technology in education.

\section{Design of Visual Education Methods}

Visual education is an educational activity that utilizes advanced information technology under the support of educational purposes and advanced technology [9]. Traditional educational and teaching methods place students in the position of passive acceptance, and visual teaching is conducive to teaching and learning cooperation so as to inspire feelings and give students initiative in learning [10]. Taking virtual reality teaching as an example, virtual reality technology provides a realistic environment, changing the enthusiasm of students with the human-computer interaction function, and from the perspective of students, visual education has advantages such as interaction, visualization and autonomy [11]. Visual education method can break the traditional region or time limit and make resource sharing become reality, and visual teaching develops from early TV teaching to distance teaching, and then to higher virtual simulation, all of which are the delivery of visual education implementations [12].

Figure 1 is the principle of visual education and teaching design, which mainly follows the principles of courseware design pedagogy, psychology and aesthetics. The purpose of education is to meet the needs of all sectors of the society. With the rapid development of information technology, traditional education and teaching methods have been gradually broken, and education has become more and more serviceoriented, selective, fair and impartial [13]. The design of teaching courseware based on visual education should still follow the basic principles of pedagogy, including artistry, friendly interface, convenient operation, and reflecting the thought of quality education [14]. Visual education should take student's participation as the core, and realize the value of education through interactive control and the teaching practice of network curriculum. Aesthetic design is a very important factor to attract students and it can directly beautify the appearance of human-computer interaction interface through color and improve people's visual impression. Taking college students' teaching as an example, vivid color and texture can attract college students' attention. 


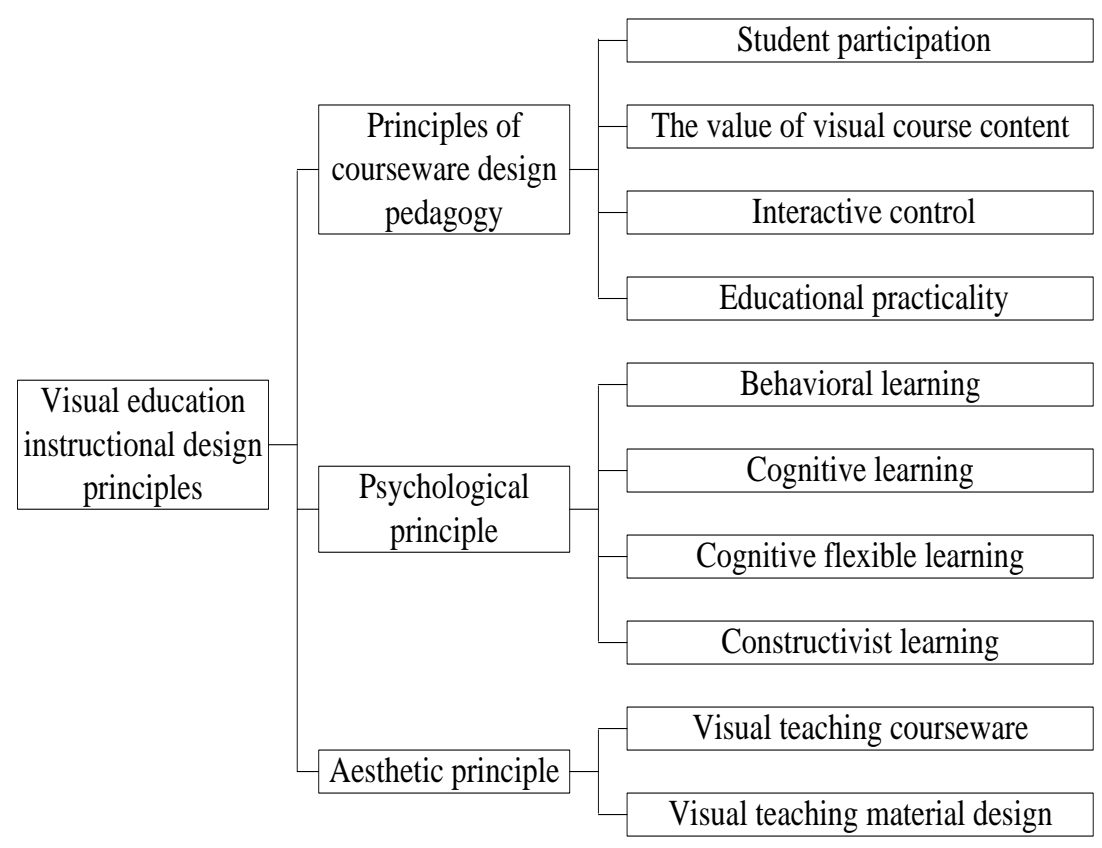

Fig. 1. Design principles of visual education and teaching

\section{Design and Implementation of Human-Computer Interaction Communication Protocol and Interaction Program}

\subsection{Design and implementation of human-computer interaction communica tion protocol}

In various applications, there are many problems to be considered in choosing which communication mode, and the human-computer interaction system should guarantee the stability, accuracy and rapidity of communication, which are important indicators ensuring the performance. Transmission distance, transmission rate and transmission cost are the important influencing factors of human-computer interaction communication. The human-computer interaction communication protocol to be designed and implemented in this paper is also designed to realize low-cost, longdistance and fast-rate transmission. Figure 2 is the working principle of the humancomputer interaction system and the whole interaction system is divided into teachshow module, control system, servo system, simulation monitoring and so on. The main communication design mode of human-computer interaction is master-slave mode, in which the data transmitted between the interface and the controller include machine parameters, instruction parameters, object codes and state parameters. 


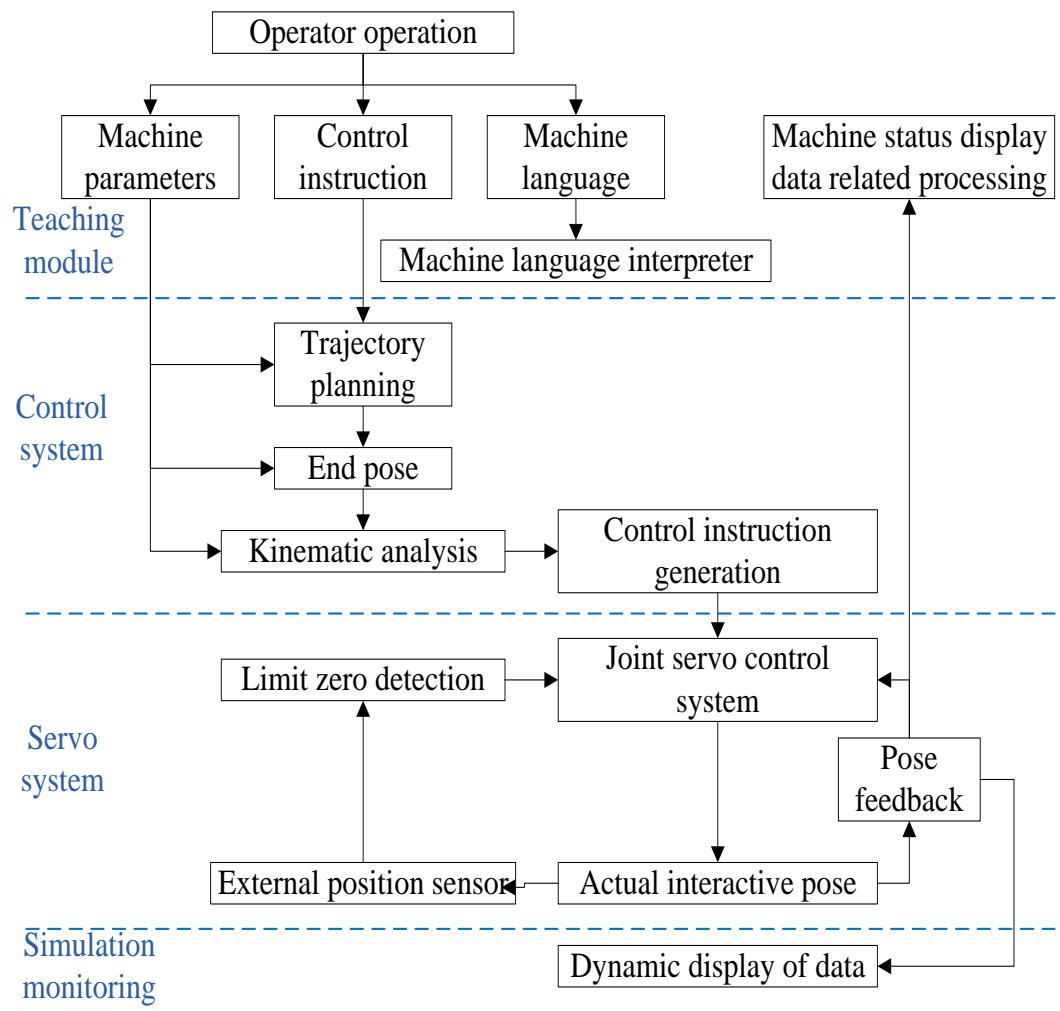

Fig. 2. Working principle of human-computer interaction system

\subsection{Design and implementation of human-computer interaction program}

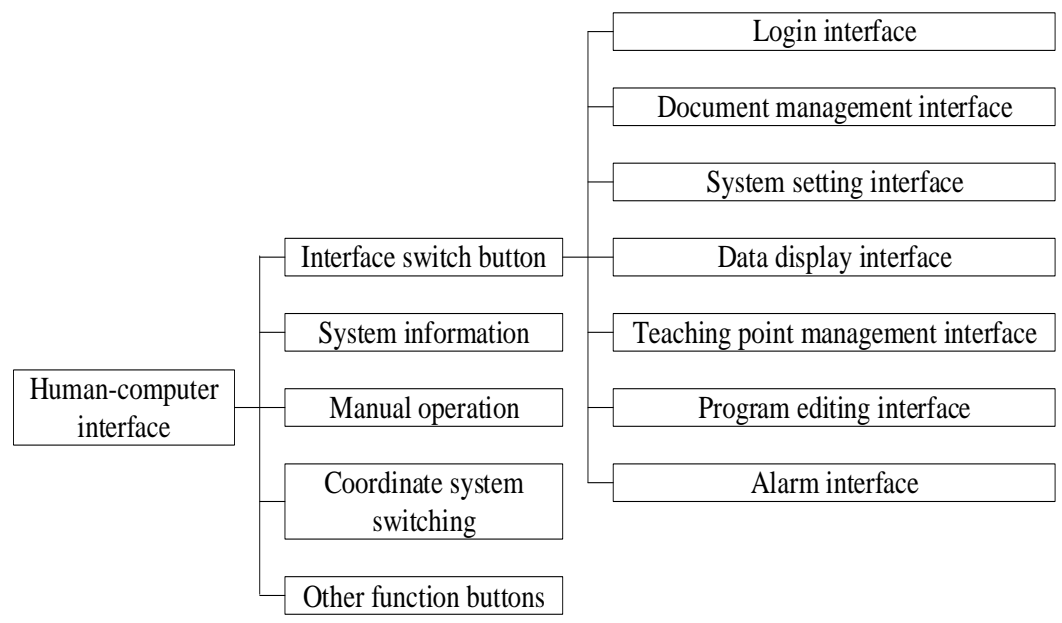

Fig. 3. Functional architecture of human-computer interface 
The design of human-computer interaction interface is controlled by programs. The human-computer interaction interface is generally divided into manual mode and automatic mode. Under the automatic mode, the functions of manual mode will be blocked. Figure 3 is a functional structure of the human-computer interaction interface, and the whole interaction interface includes an interface switch key, system information, manual operation, coordinate system switch and other function keys, and the interface switch key includes login interface, document management interface, system setting interface, data display interface, teaching point management interface, program editing interface and alarm interface. Figure 4 is a layout framework of the human-computer interaction interface. The layout and setting of the human-computer interaction interface are designed according to human comfort and convenience, and the interface switching area is a main window for presenting the contents of the human-computer interaction. Figure 5 is a functional module design of the humancomputer interaction program, which includes seven modules in total, namely multithread management of the interaction program, physical key response design, system login interface and system setting interface, teaching point management interface, program editing interface, industrial robot language interpreter and the design of soft keyboard. The status display column in the human-computer interaction system can be used to display the operation mode and status information, and the user selects the operation mode according to his own needs; in the design of human-computer interaction program, multiple threads can be created at the same time to realize the fast and long-distance interaction of information. In the process of human-computer interaction, taking the music information extraction program as an example, Figure 6 shows a cloud control module for music information, which is based on the Internet, mainly by starting cloud identification, communicating with a server, submitting the music information data to the cloud engine for analysis and delivery, and using the audio and video content server to satisfy the interaction demand of the user for the music information.

\begin{tabular}{|c|c|c|c|c|}
\hline LED & \multicolumn{3}{|c|}{ Status display bar } & \\
\hline \multirow{3}{*}{$\begin{array}{c}\text { Switch } \\
\text { interface } \\
\text { physical } \\
\text { button }\end{array}$} & \multicolumn{2}{|c|}{ Interface switching area } & $\begin{array}{c}\text { Physical } \\
\text { key } \\
\text { display } \\
\text { area }\end{array}$ & Physical \\
\hline & Interface hint & \multicolumn{3}{|c|}{ Communication connection status } \\
\hline & \multicolumn{3}{|c|}{$\begin{array}{l}\text { Physical buttons } \\
\end{array}$} & \\
\hline
\end{tabular}

Fig. 4. Human computer interface layout framework 


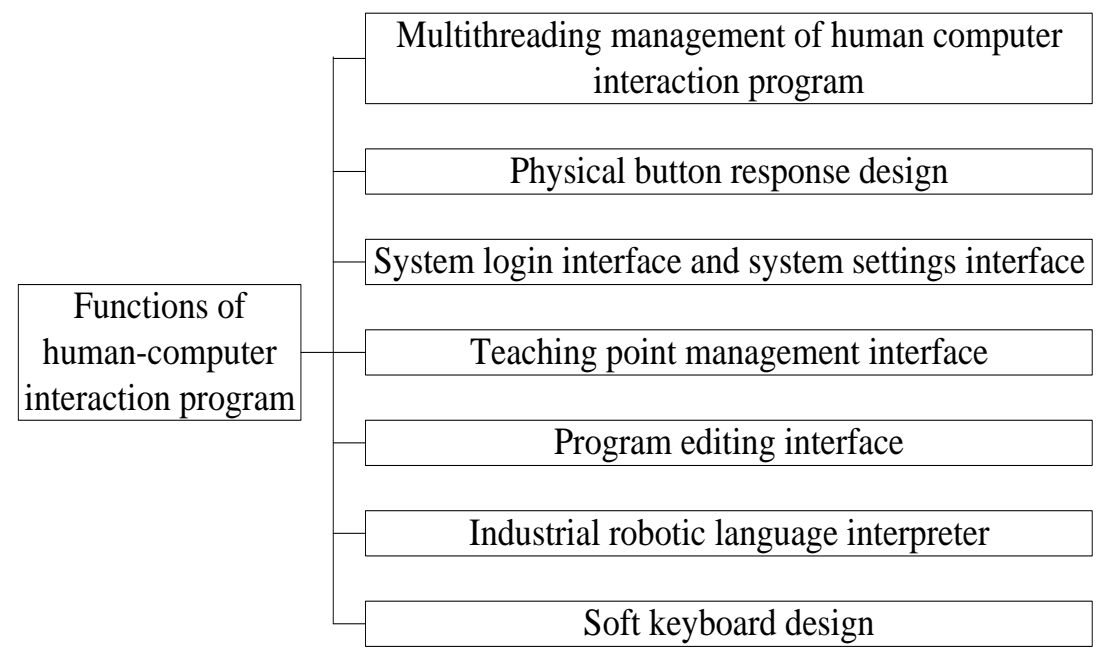

Fig. 5. Function module design of human-computer interaction program

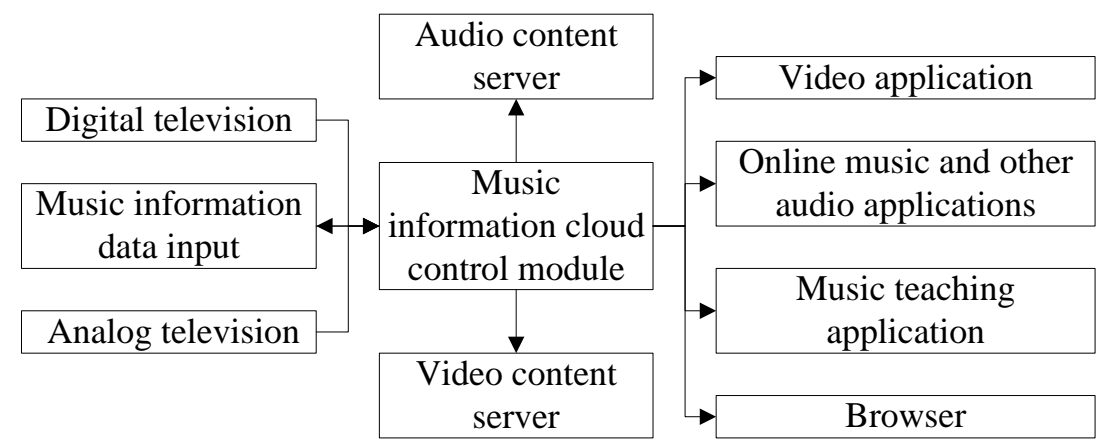

Fig. 6. Music information cloud control module

\section{Design and Realization of College students' Music Visual Edu cation and Teaching}

\subsection{Visualization module presentation of college students' music information acquisition}

With the development of music education, people gradually realize the importance of college students' music education. Music visual education is human-computer interaction with rhythm and melody and college students can directly feel and experience the changes of rhythm and melody, which plays a very important role in cultivating college students' imagination, memory and creativity. Music information includes music rhythm, music melody, music language and music style and the interaction of 
college students' music information plays a significant role in cultivating college students' intelligence, memory, attention, imagination and creativity.

In the above section, the communication and program of human-computer interaction system are analyzed. The design and realization of visual education is the process of human-computer interaction. In the process of music learning, college students perceive the strength of music rhythm and the speed of music melody through humancomputer interaction system, and accordingly show different postures, expressions and movements, which is difficult to be presented in traditional classroom education. The music MV plays with the color of picture movement and the music rhythm, driving the college students to repeat the music information and the dance movement transmitted in the MV, which will raise the learning efficiency. Figure 7 shows the acquisition of college students' music information by human-computer interaction system, which transmits the music information to the college students, and the college students' feedback the music information to the interaction system through the transmission-feedback process with the machine several times. In this way, college students can also really understand the meaning of music information. Figure 8 is an architecture of a music information data acquisition module, in which a college student obtains an audio or video data stream by means of a machine interface, and collects music information data by means of a human-computer multi-screen interaction or a Bluetooth remote controller. Figure 9 is a flow chart of college students' music information interaction in the cloud, and the college students' music information data is transmitted to the cloud identification engine and the college students' music information control module through the college students' music information collection module, thereby realizing the broadcast of the cloud service or the college students' music information, so that the college students can acquire music information. Figure 10 shows the implementation steps of college students' music information control module, namely start college students' music information cloud voice, enable music activity interface to play a pulse code modulation file, and start a cloud recognition in a callback interface of playing the pulse code modulation file; then, in the callback interface of cloud identification, control the workflow interface and start the analysis, so as to form an interaction interface for college students' music information.

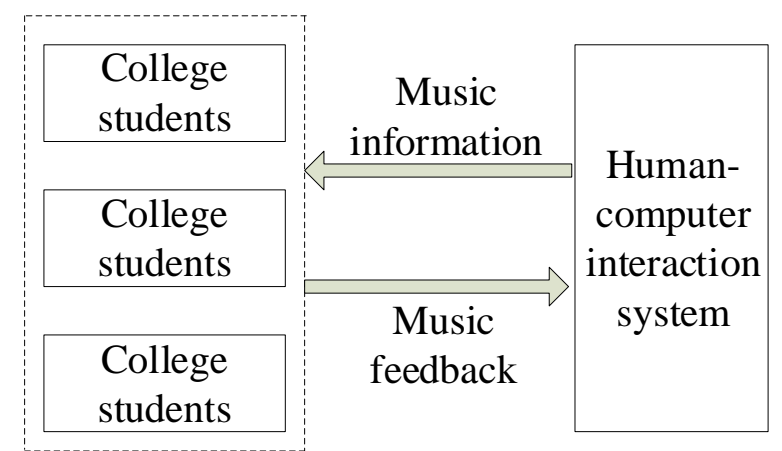

Fig. 7. College students' music information acquisition based on human-computer interaction 


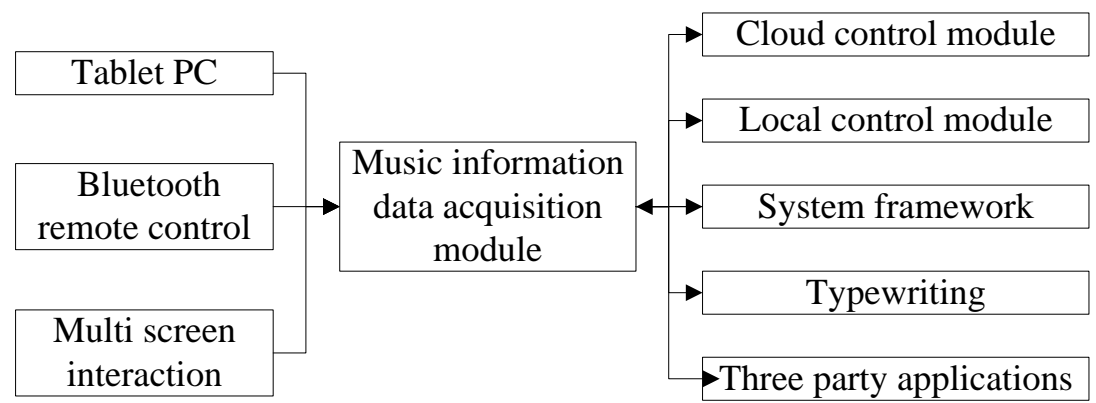

Fig. 8. Music information data acquisition module architecture

\begin{tabular}{|c|c|c|}
\hline $\begin{array}{c}\text { College students' } \\
\text { music information } \\
\text { data }\end{array}$ & $\begin{array}{c}\text { College students' music } \\
\text { information collection } \\
\text { module }\end{array}$ \\
$\qquad$ Cloud business module & $\begin{array}{c}\text { Cloud recognition } \\
\text { engine }\end{array}$ \\
$\begin{array}{c}\text { College students' } \\
\text { music information } \\
\text { control module } \\
\downarrow\end{array}$ \\
$\quad \begin{array}{c}\text { Cloud broadcast } \\
\text { module }\end{array}$ \\
\hline
\end{tabular}

Fig. 9. Flow chart of music information interaction for college students in the cloud

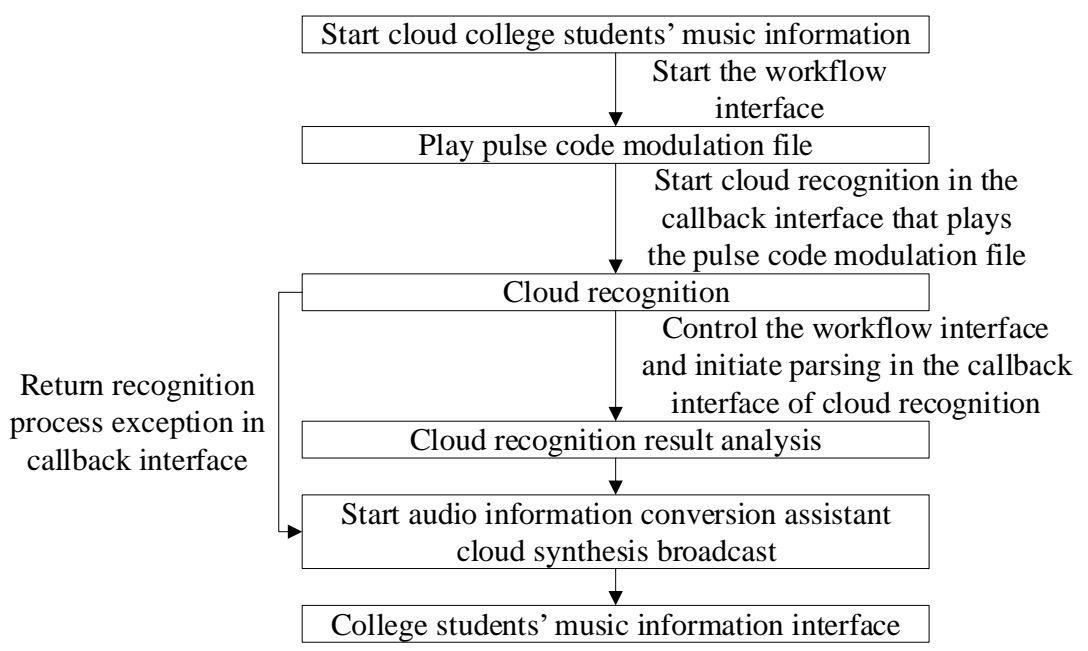

Fig. 10. Implementation steps of music information control module for college students in the cloud 


\subsection{Feasibility analysis of visual teaching in the acquisition of college students' music information}

In college students' music teaching, visual teaching makes full use of college students' eye and brain system, transforms traditional and abstract information into colorful images or animation, and thus deepens the impression of music information in college students' brain. In order to study the feasibility of visual teaching in the acquisition of college students' music information, we carry out four experimental tests, and choose the second-grade students of a university in Nanjing as respondents. The visual teaching method is used in music teaching. The interactive response values of music information acquired by college students in four classes with visual teaching methods are tested respectively. Figure 11 is an interactive response value of college students to acquire music information, Figure 11 (a) is a result of a traditional teaching method and Figures 11 (b) - (e) are results of visual teaching method. It can be clearly seen that with visual teaching method, the higher interactive response value is shown as a whole, and college students can get more music information, that's, visual education method based on human-computer interaction system is very helpful for college students to get music information.

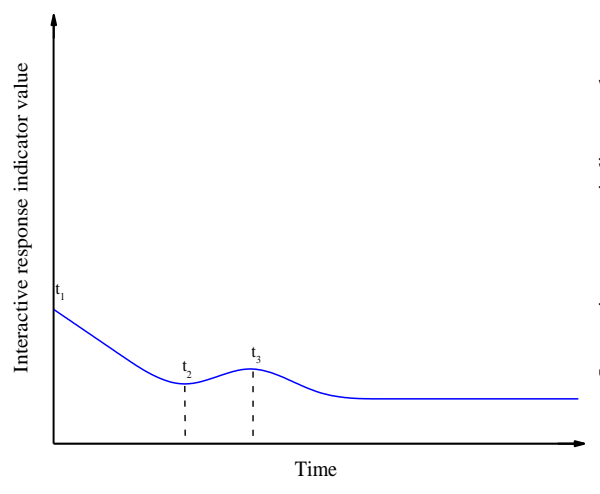

(a) Traditional teaching mode

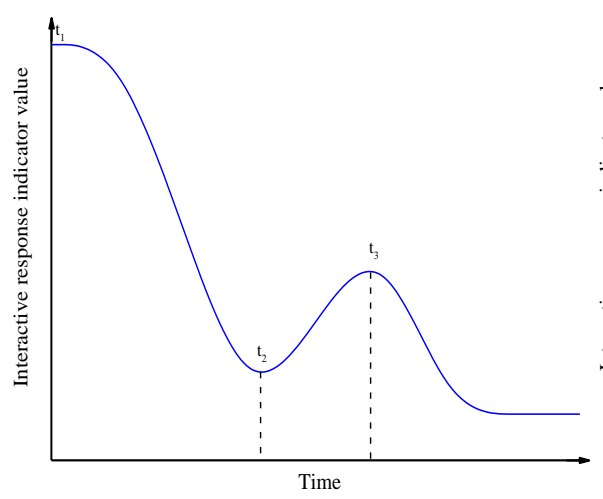

(c) Two

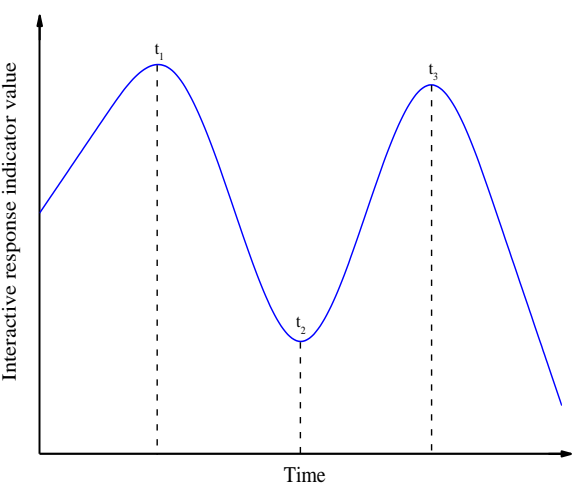

(b) One

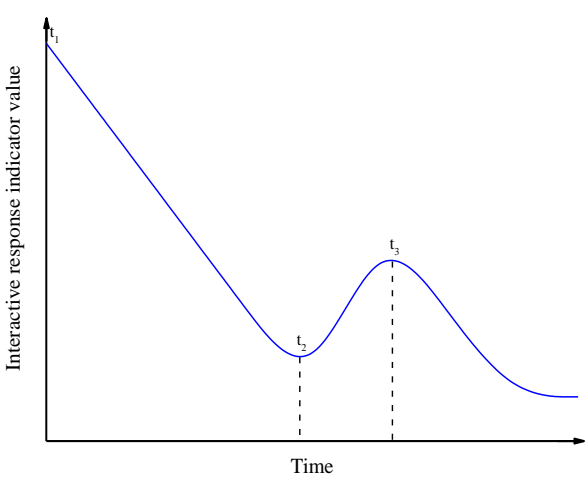

(d) Three 


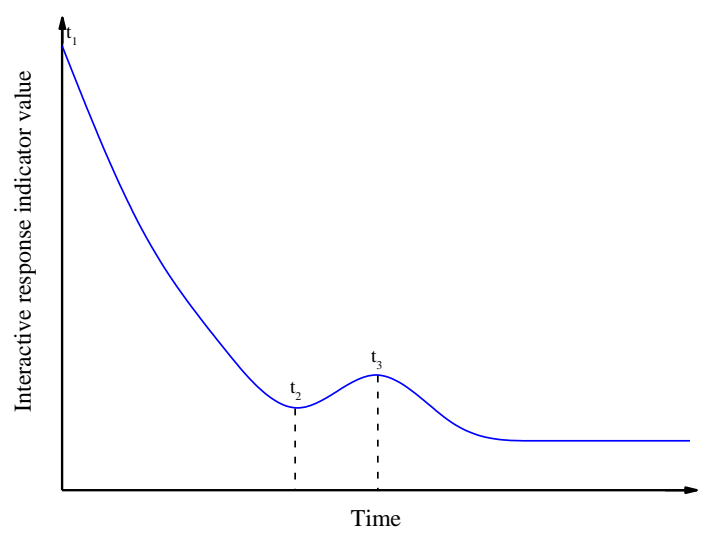

(e) Four

Fig. 11. College students' interactive response value of getting music information

\section{Conclusion}

Based on the human-computer interaction system, this paper applies the visual education method to college students' music teaching, and probes into the feasibility of its application. The concrete conclusions are as follows:

- Visual education should focus on the participation of students and realize the value of education through interactive control and online teaching practice. The visual education design should follow the principles of courseware design pedagogy, psychology and aesthetics.

- The stability, accuracy and rapidity of human-computer interaction communication are important indicators to guarantee performance, and the important influencing factors are transmission distance, transmission rate and transmission cost. The main communication design mode of human-computer interaction is master-slave mode, in which the interactive terminal and the controller transmit data including machine parameters, instruction parameters, object codes and state parameters.

- The investigation and research show that the visual education method based on human-computer interaction system is very helpful to the acquisition of college students' music information. By applying the visual teaching method, higher interactive response values can be obtained as a whole.

\section{$6 \quad$ References}

[1] Suzuki, N., Kakehi, K., Takeuchi, Y., Okada, M. (2004). Social effects of the speed of hummed sounds on human-computer interaction. International Journal of HumanComputer Studies, 60(4): 455-468. https://doi.org/10.1016/j.ijhcs.2003.09.007 
[2] Munoz-Merino, P. J., Kloos, C. D., Munoz-Organero, M. (2011). Enhancement of student learning through the use of a hinting computer e-learning system and comparison with human teachers. IEEE Transactions on Education, 54(1): 164-167. https://doi.org/10.1109/ te.2010.2045001

[3] Xia, D., Li, J., Zhou, L. (2018). Design of visual education resource Library based on 3D Modeling, International Journal of Emerging Technologies in Learning, 13(11): 170-183. https://doi.org/10.3991/ijet.v13i11.9609

[4] Han, Y. (2010). A low-cost visual motion data glove as an input device to interpret human hand gestures. IEEE Transactions on Consumer Electronics, 56(2): 501-509. https://doi. org/10.1109/tce.2010.5505962

[5] Li, S., \& Zhang, X. (2017). Implicit intention communication in human-robot interaction through visual behavior studies. IEEE Transactions on Huhuman-computer Systems, 47(4): 437-448. https://doi.org/10.1109/thms.2017.2647882

[6] Kamburov, A., Stelzl, U., Lehrach, H., Herwig, R. (2012). The ConsensusPathDB interaction database: 2013 update. Nucleic acids research, 41(D1): D793-D800. https://doi. org/10.1093/nar/gks1055

[7] Luo, M. (2018). Matlab-realized visual A* path planning teaching platform. International Journal of Emerging Technologies in Learning, 13(10), 196-207. https://doi.org/10.3991/ij et.v13i10.9463

[8] Biondi, F., Alvarez, I., Jeong, K. A. (2019). Human - system cooperation in automated driving. International Journal of Human-Computer Interaction, 35(11): 917-918. https:// doi.org/10.1080/10447318.2018.1561793

[9] Porta, A., Herrera, L. (2017). Music and its significance in children favourite audiovisuals. Comunicar: Media Education Research Journal, 25(52): 83-91.52, 83-91. https://doi.org/ $\underline{10.3916 / \mathrm{c} 52-2017-08}$

[10] Lu, X., Li, P., Chen, B., Chen, Y. (2011). Computer simulation of the dynamic layered soil-pile-structure interaction system. Canadian Geotechnical Journal, 42(3): 742-751. https://doi.org/10.1139/t05-016

[11] Lin, H. C., Chiu, Y. H., Chen, Y. J., Wuang, Y. P., Chen, C. P., \& Wang, C. C., Huang, C. L., Wu, T. M., Ho, W. H. (2017). Continued use of an interactive computer game-based visual perception learning system in children with developmental delay. International Journal of Medical Informatics, 107: 76-87. https://doi.org/10.1016/j.ijmedinf.2017.09.003

[12] Sechopoulos, I. (2012). WE-G-BRA-02: visual demonstrations of medical physics concepts of transmission imaging for resident education. Medical Physics, 39(6): 3969. https://doi.org/10.1118/1.4736197

[13] Shen, Y., Kuai, S., Zhou, W., Peng, S., Tian M, Liu, K., Zhou, X. (2014). Study of preferred background luminance in watching computer screen in children. Chinese medical journal, 127(11): 2073-2077. https://doi.org/10.3760/cma.j.issn.0366-6999.20133232

[14] Amber, K. T., Ledon, J. A., Savas, J. A., Dusseault, S. K., \& Nouri, K. (2015). Visual identification of skin cancer in beachgoers: A need for improved education on nonmelanoma skin cancer in the general population and melanoma in the african- american population. International Journal of Dermatology, 54(3): 85-87. https://doi.org/10.1111/ijd. $\underline{12684}$

\section{Author}

Yifeng Li graduated from music college of China with a master's degree. He works in the school of art of northeast agricultural university and is engaged in opera singing 
and teaching. He has published many core papers. His research interests include electronic digital music, multimedia music technology and music education and teaching management.

Article submitted 2019-10-27. Resubmitted 2019-11-28. Final acceptance 2019-11-29. Final version published as submitted by the authors. 